\title{
CONCENTRAÇÃO DE CAFEÍNA EM Camellia sinensis
}

\section{CONCENTRATION OF CAFFEINE IN Camellia sinensis}

\section{Daniele Nascimento Silva ${ }^{1}$, Marielle Flaviane de Carvalho Pimentel ${ }^{1}$; Daniel Ângelo Macena ${ }^{1}$; Vinícius Marques Gomes ${ }^{1}$.}

\author{
${ }^{1}$ Universidade do Oeste Paulista, Curso de Química Bacharelado, Presidente Prudente, \\ São Paulo. \\ e-mail: viniciusmarques@unoeste.br
}

RESUMO - Considerando que o chá é a segunda bebida mais consumida no mundo é importante não haver excesso de cafeína em sua composição já que ela causa alguns efeitos fisiológicos à saúde humana como o diurético e a dependência química. O presente projeto teve como objetivo comparar os resultados obtidos da determinação de cafeína em chás provenientes da espécie Camellia sinensis com os encontrados na literatura. Para isso, foram utilizadas três amostras de chá branco, três de chá verde e três de chá preto de mesma marca. As análises foram realizadas em triplicatas e a cafeína determinada por espectrofotometria na região do ultravioleta. 0 chá preto apresentou o maior teor de cafeína $(0,106 \mathrm{mg} / \mathrm{g})$, o chá branco $0,082 \mathrm{mg} / \mathrm{g}$ e o chá verde o menor $(0,067 \mathrm{mg} / \mathrm{g})$. No entanto, os três tipos de chás apresentam baixas concentrações ao serem comparados com a literatura que apresentou valores entre 14,3 e 40,0 mg/g de cafeína de chá.

Palavras-chave: alcaloide; estimulante; chá verde; chá branco; chá preto.

ABSTRACT - Considering that tea is the second most consumed drink in the world it is important not to have excess caffeine in its composition since it causes some physiological effects to human health such as diuretic and chemical dependence. The present project had as objective to compare the results obtained from the determination of caffeine in teas from the Camellia sinensis species with those found in the literature. For that, three samples of white tea, three of green tea and three of black tea of the same brand were used. The analyzes were performed in triplicates and caffeine determined by spectrophotometry in the ultraviolet region. Black tea had the highest caffeine content $(0.106 \mathrm{mg} / \mathrm{g})$, white tea $0.082 \mathrm{mg} / \mathrm{g}$ and green tea the lowest $(0.067$

Recebido em: 23/08/2018 Revisado em: 19/09/2018 Aprovado em: 21/09/2018 $\mathrm{mg} / \mathrm{g}$ ). However, the three types of teas have low concentrations when compared to the literature that presented values between 14.3 and 40.0 $\mathrm{mg} / \mathrm{g}$ of caffeine of tea.

Keywords: alkaloid; stimulant; green tea; white tea; black tea. 


\section{INTRODUÇÃO}

O chá é a segunda bebida mais consumida no mundo e seus efeitos a saúde têm sido constantemente estudados, evidenciando que o seu consumo pode reduzir os níveis de colesterol, hipertensão, além de seus efeitos antioxidantes e antimicrobianos, proteção contra doenças cardiovasculares e câncer (PAGANINI-COSTA; DA SILVA, 2011).

Deve ser levado em conta que a composição química pode variar de acordo com a espécie no preparo das folhas do chá, com a idade dessas folhas, o clima e condições de cultivo (BORTOLINI; SICKA; FOPPA, 2010). Folhas, flores, frutos e raízes, são utilizados para o preparo do chá, porém nem todas as espécies vegetais e nem qualquer parte da planta pode ser utilizado. O preparo é tradicionalmente, por infusão (adicionar água fervente a planta e abafar o sistema por 2 a 3 minutos) ou a decocção em água (fervura da planta por 2 a 5 minutos). Sendo a decocção a mais utilizada para partes mais duras da planta, como cascas (SESA, 2013; DE MORAIS et al., 2009).

A Camellia sinensis (L.) Kuntze é um arbusto ou árvore de pequeno porte da que pertence à família Theaceae, de origem asiática, bem adaptada e cultivada no Brasil. Os principais tipos de chás provenientes dessa espécie são distinguíveis pelo processamento, sendo eles, o chá branco, o chá verde, amarelo e o preto. O nível de oxidação é o que determina o tipo de chá que será obtido (MATSUBARA; RODRIGUESAMAYA, 2006; SILVA, 2010).

Cultivada em mais de 30, países tropicais e subtropicais, a Camellia sinensis, possui flores parecidas com as das camélias e devido a isso o significado do seu nome científico em latim é camélia da China (LIMA et al., 2009).

É importante destacar que só a Camellia sinensis, apresenta uma diversidade em sua composição química (polifenóis, alcaloides, minerais etc.), o que se observa uma diversidade de sabores e aromas conforme as condições de cultivo, coleta, preparo e acondicionamento das folhas (RETO et al. , 2008).

Os chás provenientes da Camellia sinensis, tem uma característica importante. Todos eles possuem cafeína em sua composição química. $\mathrm{Na}$ planta estão presentes componentes químicos considerados fortes oxidantes. As reações de oxidação-redução que ocorrem em suas folhas são a principal diferença entre os tipos de chá provenientes da Camellia sinensis. As enzimas polifenoloxidases e peroxidades que são liberadas dos vacúolos celulares quando as plantas são picadas ou trituradas e são expostas ao oxigênio do ar, catalisam essas reações (MATSUBARA; AMAYA-RODRIGUES, 2006).

O chá é um produto composto de uma ou mais partes de espécies vegetais moídas, com ou sem fermentação, tostadas ou não, conforme definido pela legislação brasileira, constantes no Regulamento Técnico de Espécies Vegetais para o preparo de chás (BRASIL, 2005).

O seu consumo foi consolidado e hoje representa grande importância socioeconômica. Aproximadamente três bilhões de toneladas são produzidas anualmente no mundo (KHAN; MUKHTAR, 2007 apud BRAIBANTE et al., 2014). Porém o seu consumo tem sido menor do que sua produção, o que acarretou a redução do seu preço. No Brasil, seu cultivo está concentrado no Vale da Ribeira no estado de São Paulo, porém quase toda a produção é exportada (LIMA et al., 2009).

Devido sua capacidade antioxidante, seu farto uso na dieta de milhares de pessoas em todo mundo, tem atraído muita atenção nos últimos anos. Os chás são ricos em micronutrientes minerais fundamentais, em catequinas e flavonóides, compostos que contem atividade antioxidante e são classificados como agentes sequestrantes de radicais livres. O preparo dos chás através da infusão auxilia na extração para a bebida desses compostos benéficos a saúde (HIGDON; FREI, 2003; MENDEL; YOUDIM, 
2004; BUNKOVA et al., 2005 apud DE MORAIS et al., 2009).

O chá branco é preparado a partir de folhas novas da Camellia sinensis retiradas antes que as flores desabrochem, cujo os botões são protegidos e não sofreram oxidação. É o menos processado e limita-se apenas na lavagem e secagem das folhas e brotos selecionados da Camellia sinensis (TEIXEIRA et al., 2015).

O chá preto e derivado das folhas envelhecidas pela oxidação aeróbica das catequinas, catalisada enzimaticamente (SENGER; SHWNKE; GOTTLIEB, 2010). O chá passa por várias etapas de processamento, dentre elas a de "fermentação", que consiste, na verdade, de oxidação enzimática dos flavanóis e teaflavinas, que constituem um grupo característico deste tipo de chá (MATSUBARA, RODRIGUES-AMAYA, 2006; PEREIRA, 2010).

O chá verde não é fermentado e seu preparo é a partir das folhas frescas da planta, após uma rápida inativação da enzima polifenoloxidase, pelo emprego de vaporização e secagem, o que mantem conservado seu teor de polifenóis e o torna mais rico em catequinas que os demais. A ingestão do chá traz benefícios para a saúde e podem auxiliar no tratamento de doenças cardiovasculares (SENGER; SHWNKE; GOTTLIEB, 2010).

A cafeína (1,3,7-trimetilxantina) é encontrada principalmente em chás, cafés, produtos de cacau e bebidas à base de cola (DE MARIA; MOREIRA, 2007).

A cafeína presente nos chás pode gerar alguns efeitos fisiológicos no organismo humano, sendo os principais o efeito diurético e a dependência química. Pode causar o aumento da taxa metabólica, relaxamento da musculatura lisa dos brônquios, do trato biliar, do trato intestinal e de partes do sistema vascular (BRENELLI, 2003; MATSUBARA; RODRIGUEZ-AMAYA, 2006).

A cafeína é um alcalóide, um composto que contém nitrogênio que apresenta propriedades básicas.
Pertencentes as xantinas, uma classe de compostos de ocorrência natural. Possivelmente, as xantinas são os estimulantes mais antigos conhecidos sendo que, a cafeína é um dos mais fortes. Pode ser detectada no corpo humano após 5 minutos do consumo e após 20-30 minutos, atinge o seu efeito estimulante máximo. Ela é metabolizada pelo fígado e tem tempo de meia vida por volta 3-6 horas, não sendo acumulada no organismo.

Sua ingestão em excesso pode causar vários sintomas desagradáveis, sendo a irritabilidade, dores de cabeça, insônia, diarreia e palpitações do coração (BRENELI, 2003; RETO et al., 2008).

O efeito do consumo de cafeína sobre o sistema cardiovascular ainda é motivo de grandes questionamentos, pois o consumo regular pode elevar a pressão arterial de forma persistente, e desta forma, pessoas com hipertensão, doença coronariana e arritmia cardíaca deveriam reduzir seus níveis de ingestão de cafeína (DE MARIA; MOREIRA, 2007; TEIXEIRA et al., 2015).

Este projeto teve como objetivo determinar as concentrações de cafeína em amostras de chás branco, preto e verde da espécie Camellia sinensis adquiridas em supermercados do município de Presidente Prudente e comparar com as legislações vigentes.

\section{MÉTODO}

Os estudos foram realizados no Laboratório do Bloco Q do setor de Química, e no Laboratório de Ecofisiologia Vegetal no Bloco B1, que se encontra na Universidade do Oeste Paulista, no Campus 2 no km 572 Rodovia Raposo em Presidente Prudente SP.

As amostras foram adquiridas em supermercados do município de Presidente Prudente. Foram selecionadas três amostras das folhas e talos de chá branco, três de chá verde e três de chá preto da mesma marca. As análises foram realizadas em 3 triplicatas para cada amostra. 
A metodologia utilizada para a extração da cafeína baseou-se em Schormüller (1970). Primeiramente pesou-se 2,0 g de amostra do chá em um erlenmeyer, em seguida adicionou-se 5,0 g de óxido de magnésio e logo após $200 \mathrm{~mL}$ de água destilada. Ferveu-se a mistura por 60 minutos na manta de aquecimento por 5 minutos sob agitação constante num agitador magnético, repondo-se a água perdida por evaporação. Após o resfriamento, filtrou-se a mistura através de filtração a vácuo e colocou-se o filtrado a em um funil de separação com $4,0 \mathrm{~mL}$ de $\mathrm{H}_{2} \mathrm{SO}_{4}$ (1+9, v/v em água). Extraiu-se 5 vezes com 20 $\mathrm{mL}$ de clorofórmio em outro funil de separação e adicionou-se $5 \mathrm{~mL}$ de $\mathrm{KOH}$ aquoso a $1 \%$. Agitou-se por 1 minuto para que se separassem as fases. Filtrou-se a fase clorofórmica através de algodão para um balão volumétrico de $100 \mathrm{~mL}$ e completou-se o volume com clorofórmio. Transferiu-se uma alíquota de $2,0 \mathrm{~mL}$ para o balão volumétrico de $50 \mathrm{~mL}$ e completou-se o volume com clorofórmio.

A determinação também foi baseada na metodologia de Schormüller (1970). As absorbâncias foram lidas no Espectrofotometro-Bel-UV-M51-UV-VISIVEL a $272 \mathrm{~nm}$, com utilização de cubeta de Quartzo com caminho ótico de $10 \mathrm{~mm}$.

A quantificação foi realizada utilizando-se uma curva analítica, cujas concentrações variaram entre 0,2 e $1,0 \mathrm{mg}$ de cafeína/L em clorofórmio. Após as leituras das absorbâncias dos padrões, construiu-se um gráfico e a partir dos valores de absorbância calculou-se a concentração de cafeína em $\mathrm{mg} / \mathrm{L}$ de cada amostra analisada.

As concentrações foram calculadas pela equação da reta $(y=a x+b)$. Onde $y=$ absorbância; $a$ = coeficiente angular da curva; $X=$ concentração; $b=$ coeficiente linear $d a$ curva.

\section{RESULTADOS}

Os resultados foram tratados por comparação de médias e apresentados através de gráficos e tabelas. Comparou-se a concentração de cafeína nos chás provenientes da Camellia sinensis com os resultados encontrados na literatura.

Tabela 1. Construção da curva analítica.

\begin{tabular}{c|c|c}
\hline Pontos & $\begin{array}{c}\text { Absorbância } \\
\text { (272 } \mathbf{~ n m})\end{array}$ & $\begin{array}{c}\text { Concentração } \\
\text { (mg/L) }\end{array}$ \\
\hline Branco & 0,000 & 0,000 \\
\hline 1 & 0,349 & 0,200 \\
\hline 2 & 0,817 & 0,400 \\
\hline 3 & 1,270 & 0,600 \\
\hline 4 & 1,879 & 0,800 \\
\hline 5 & 2,204 & 1,000 \\
\hline
\end{tabular}

Fonte: próprio autor.

Gráfico 1. Curva analítica

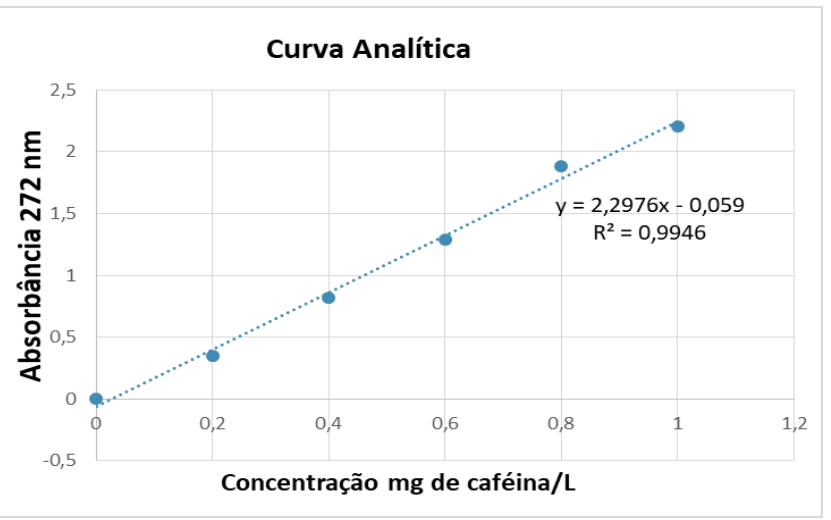

Fonte: próprio autor.

A TABELA 1 apresenta os dados utilizados para a construção da curva analítica dos padrões de cafeína

A concentração é pré-estabelecida através da realização de cálculos ao preparar a solução estoque utilizada para os pontos da curva analítica. A curva analítica está representada no GRÁFICO 1.

Os resultados obtidos por espectrofotometria para as amostras de chá branco, verde e preto são apresentados nas TABELAS 2, 3 e 4 respectivamente. 
Tabela 2. Resultados das análises das amostras de chá branco.

Fonte: próprio autor.

\begin{tabular}{c|c|c|c}
\hline Amostra & $\begin{array}{c}\text { Massa } \\
(\mathrm{g})\end{array}$ & $\begin{array}{c}\text { Absorbância } \\
(272 \mathrm{~nm})\end{array}$ & $\begin{array}{c}\text { Concentração } \\
(\mathrm{mg} / \mathrm{g})\end{array}$ \\
\hline 1 & 2,0043 & 0,566 & 0,068 \\
\hline 2 & 2,0019 & 0,576 & 0,069 \\
\hline 3 & 2,0017 & 0,497 & 0,060 \\
\hline 4 & 2,0092 & 1,372 & 0,156 \\
\hline 5 & 2,0063 & 0,421 & 0,052 \\
\hline 6 & 2,0009 & 0,526 & 0,064 \\
\hline 7 & 2,0052 & 0,952 & 0,110 \\
\hline 8 & 2,0048 & 0,735 & 0,086 \\
\hline 9 & 2,0051 & 0,611 & 0,073 \\
\hline
\end{tabular}

Tabela 3. Resultados das análises das amostras de chá verde.

\begin{tabular}{c|c|c|c}
\hline Amostra & $\begin{array}{c}\text { Massa } \\
(\mathrm{g})\end{array}$ & $\begin{array}{c}\text { Absorbância } \\
(272 \mathrm{~nm})\end{array}$ & $\begin{array}{c}\text { Concentração } \\
(\mathrm{mg} / \mathrm{g})\end{array}$ \\
\hline 1 & 2,0010 & 0,466 & 0,057 \\
\hline 2 & 2,0020 & 0,343 & 0,044 \\
\hline 3 & 2,0025 & 0,773 & 0,091 \\
\hline 4 & 2,0094 & 0,577 & 0,069 \\
\hline 5 & 2,0048 & 0,297 & 0,039 \\
\hline 6 & 2,0024 & 0,686 & 0,081 \\
\hline 7 & 2,0079 & 0,449 & 0,055 \\
\hline 8 & 2,0038 & 0,462 & 0,057 \\
\hline 9 & 2,0017 & 0,940 & 0,109 \\
\hline
\end{tabular}

Fonte: próprio autor.

Tabela 4. Resultados das análises das amostras de chá preto.

Fonte: próprio autor.

\begin{tabular}{c|c|c|c}
\hline Amostra & $\begin{array}{c}\text { Massa } \\
(\mathrm{g})\end{array}$ & $\begin{array}{c}\text { Absorbância } \\
(272 \mathrm{~nm})\end{array}$ & $\begin{array}{c}\text { Concentração } \\
(\mathrm{mg} / \mathrm{g})\end{array}$ \\
\hline 1 & 2,0028 & 1,178 & 0,135 \\
\hline 2 & 2,0053 & 0,663 & 0,079 \\
\hline 3 & 2,0046 & 1,117 & 0,128 \\
\hline 4 & 2,0065 & 0,846 & 0,098 \\
\hline 5 & 2,0043 & 0,965 & 0,111 \\
\hline 6 & 2,0051 & 0,878 & 0,102 \\
\hline 7 & 2,0079 & 1,135 & 0,130 \\
\hline 8 & 2,0003 & 0,813 & 0,095 \\
\hline 9 & 2,0009 & 0,663 & 0,079 \\
\hline
\end{tabular}

\section{DISCUSSÃO}

A partir dos resultados obtidos após análise das amostras, o chá preto apresentou maior concentração de cafeína, uma média de 0,106 mg de cafeína por grama do chá. Os chás branco e verde, apresentaram por sua vez, média de 0,082 e 0,067 mg/g de cafeína respectivamente. Desta forma, de acordo com o experimento realizado, as folhas de chá verde possuem menor concentração de cafeína. Segundo a literatura (PEREIRA et al., 2009), as folhas de Camellia sinensis, utilizadas para o preparo dos chás, 
apresentam teores de cafeína entre 20 e 40 mg por grama de chá.

As concentrações de cafeína apresentaram pequenas variações entre os tipos de chás da Camellia sinensis. Isso pode ter ocorrido devido ao processamento a que cada chá é submetido e o ao seu modo de preparo. $O$ método empregado não necessitou da utilização de temperatura controlada, uma vez que por se tratar de um solvente orgânico volátil utilizado na extração, foi necessário proceder imediatamente as leituras no espectrofotômetro. A determinação da cafeína foi realizada anteriormente por outros autores já citados neste trabalho (PEREIRA et al., 2009), por outros métodos como titulometria e CLAE.

Não existe uma legislação vigente específica que determine o valor máximo de cafeína em chás da espécie vegetal Camellia sinensis, porém quando comparado aos valores encontrados por Camara et al., (2015), verifica-se que os resultados encontrados no presente trabalho para os chás branco, verde e preto, estão abaixo dos valores encontrados anteriormente para as folhas da espécie vegetal Camellia sinensis que foi de 14,3 a $34,8 \mathrm{mg} / \mathrm{g}$ para folhas.

Conclui-se que todas as amostras analisadas apresentaram cafeína em sua composição, mas verificou-se que as concentrações de cafeína estão bem abaixo do que as encontradas em trabalhos anteriores de Pereira et al., (2009), Camara et al., (2015). A divergência de valores pode ter ocorrido devido à utilização dos métodos de extração com clorofórmio e determinação empregados ou até mesmo pelas marcas utilizadas para as análises.

\section{CONSIDERAÇÕES FINAIS}

A quantificação de cafeína contida em chás se faz necessária já que também está presente em diversos tipos de bebidas, sendo popularmente conhecida como estimulante, e que seu consumo em excesso pode acarretar em danos à saúde humana.
O método utilizado para a determinação é o mais rápido, simples e preciso que as técnicas gravimétricas, porém os resultados ainda podem ser superestimados pela presença de interferentes (DE MARIA; MOREIRA, 2007).

Através dos resultados obtidos por intermédio das análises, identificou-se que os chás da Camellia sinensis apresentam baixos níveis de cafeína. Porém é importante ressaltar que a ingestão em excesso da cafeína pode apresentar risco à saúde dos consumidores.

Vale frisar que as autoridades responsáveis pela legislação desses produtos, devem fiscalizar tais bebidas e que a população deve ser orientada quanto ao teor de cafeína presente nesses produtos. Para isso é necessário que a informação seja representada de uma forma que o consumidor possa se iterar dessa informação, tanto da quantidade existente quanto ao limite máximo estabelecido para o consumo.

\section{REFERÊNCIAS}

BRASIL. Ministério da Saúde. ANVISA Agência Nacional de Vigilância Sanitária. Resolução RDC no 273, de 22 de setembro de 2005. Brasilia: ANVISA, 2005.

BRAIBANTE, M. E. F.; SILVA, D.; BRAIBANTE, H. T. S.; PAZINATO, M. S. A Química dos chás. Revista Química Nova na Escola, v. 36, n. 3, p. 168 - 175, ago., 2014.

BRENELLI, E. C. S. A extração de cafeína em bebidas estimulantes- Uma nova abordagem para experimento clássico em química orgânica. Química Nova, v. 26, n. 1, p 136138, 2003. https://doi.org/10.1590/S010040422003000100023

BORTOLINI, K.; SICKA, P.; FOPPA, T.

Determinação do teor da cafeína em bebidas estimulantes. Revista Saúde, v. 4, n. 2, p. 2327, 2010. 
CAMARA, M.M. et al. Determinação dos níveis de cafeína em chás, sua transferência para a Infusão e estimativa de ingestão. 2015. 8 f. Iniciação Científica (Graduação em Ciência Farmacêutica) - Pontifícia Universidade Católica, Campinas, 2015.

DE MORAIS, S. M. et al. Ação antioxidante de chás e condimentos de grande consumo no Brasil. Braz. J. Pharmacognosy, v. 19, n. 1B, p. 315-320, 2009.

https://doi.org/10.1590/S0102$\underline{695 \times 2009000200023}$

LIMA, J.D.; MAZZAFERA, P.; MORAES, W.S.; SILVA, R.B. Chá: aspectos relacionados à qualidade e perspectivas. Ciência Rural, v. 39, n.4, p. 1270-1278, jul. 2009. https://doi.org/10.1590/S010384782009005000026

MARIA, A. B.; MOREIRA, R. F. A., Cafeína: Revisão sobre métodos de análise. Química Nova, Rio de Janeiro, v. 30, n. 1, p. 99-105, 2007.

MATSUBARA, S.; RODRIGUEZ-AMAYA, D. B. Conteúdo de miricetina, quercetina e kaempferol em chás comercializados no Brasil. Ciência e Tecnologia de Alimentos, v. 26, n. 2, p. 380-385, 2006. https://doi.org/10.1590/S0101$\underline{20612006000200021}$

PAGANINI-COSTA, P.; CARVALHO DA SILVA, D. Uma xícara (chá) de química. Revista Virtual de Química, v. 3, n. 1, p. 27-36, 2011.

PEREIRA, A. V. et al. Determinação de Compostos Fenólicos em Amostras Comerciais de Chás verde e preto - Camellia sinensis (L.) Kuntze, Theaceae. Acta Scientiarum. Health Sciences, Maringá, v. 31, n. 2, p. 119-124, 2009.

PEREIRA, L. L. S. et al. Atividade das glicosidases na presença de chá verde e de chá preto. Revista Brasileira de Plantas
Medicinais, Botucatu, v. 12 , n. 4, p. 516-518, out. 2010.

RETO, M. et al. Teor de fluoretos em infusões de chá verde (Camellia sinensis). Química Nova, v. 31, n. 2, p. 317-320, 2008. https://doi.org/10.1590/S010040422008000200024

SENGER, A. E. V.; SCHWANKE, C. H. A; GOTTLIEB, M. G. V. Chá verde (Camellia sinensis) e suas propriedades funcionais nas doenças crônicas não transmissíveis. Scientia Medica, v. 20, n. 4, p. 292-300, 2010.

PARANÁ. Secretaria de Estado da Saúde do Paraná. Comercialização de chás (alimentos) e fitoterápicos (medicamentos). Nota técnica $\mathrm{n}$ 11/13 - DVVSA/DVVSP/CEVS/SESA - 10 de dezembro, Curitiba, 2013.

SCHORMÜLLER, J. Handbuch der Lebensmmittelchemie. New York: SpringVerlag. Band VI. , 1970. p. 82-83 e 206-207

SILVA, S. R. D. S.; OLIVEIRA, T. T. D.; ;NAGEM, T. J. ; Uso do chá preto (Camellia sinensis) no controle do diabetes mellitus. Revista de Ciências Farmacêuticas Básica e Aplicada, v.31, n. 3, p. 133-142, 2010.

TEIXEIRA, V. M. et al. Estudo da Ação Inibidora do Extrato de Camellia sinensis na Corrosão do Aço-carbono 1020 em HCl 1 mol $\mathrm{L}^{-1}$. Revista Virtual de Química, v. 7, n. 5, p. 1780-1794, 2015. 